\title{
Preliminary Assessment of Salvadora persica Whitening Effects on Extracted Stained Teeth
}

\author{
Nadia Halib ${ }^{1 *}$, Nabilah Bt Nuairy ${ }^{1}$, Haslinda Ramli ${ }^{1}$, Ishak Ahmad ${ }^{2}$, Norinsan Kamil Othman ${ }^{3}$, \\ Salihatun Md Salleh ${ }^{4}$, Saiful Bahari Bakarudin ${ }^{5}$ \\ ${ }^{1}$ Faculty of Dentistry, Universiti Sains Islam Malaysia, Level 15, Tower B, Persiaran MPAJ, Jalan Pandan Utama, Pandan Indah, Kuala Lumpur, Malaysia. \\ ${ }^{2}$ School of Chemical Sciences and Food Technology, Faculty of Science and Technology, Universiti Kebangsaan Malaysia, UKM Bangi, Selangor Darul \\ Ehsan, Malaysia. ${ }^{3}$ Materials Science Programme, School of Applied Physics, Faculty of Science and Technology, Universiti Kebangsaan Malaysia, 43600 \\ Bangi, Selangor Darul Ehsan, Malaysia. ${ }^{4}$ Faculty of Mechanical and Manufacturing Engineering, Universiti Tun Hussein Onn Malaysia, 86400 Batu Pahat, \\ Johor, Malaysia. ${ }^{5}$ Institute of Microengineering and Nanoelectronics (IMEN), Level 4, Research Complex, Universiti Kebangsaan Malaysia, 43600 Bangi, \\ Selangor, Malaysia
}

\section{ARTICLE INFO}

Article history:

Received on: 18/02/2017

Accepted on: 12/06/2017

Available online: $30 / 12 / 2017$

\section{Key words:}

S. persica, abrasive, whitening properties, discolouration.

\begin{abstract}
The roots, twigs and stems of Salvadora persica (S. persica) also known as miswak have been used for centuries as oral hygiene tools. The cleansing efficacy of $S$. persica is thought to be attributed to the mechanical effects of its fibres. However, there is no study focus on $S$. persica whitening behaviour. Therefore, this study is conducted to preliminarily assess the whitening effects of $S$. persica on coffee and tea stained teeth. The bark of S. persica stems were peeled off and the pulps were dried and ground to produce powder. Scanning Electron Microscopy (SEM) and Energy dispersive X-ray spectroscopy (EDX) were carried out to study the properties of S. persica fibre. SEM revealed the presence of crystals of various shapes and sizes that act as natural abrasive agents and might contribute to its whitening effects while EDX identified that these minerals constitute of $\mathrm{O}(43.44 \mathrm{wt} \%)$, $\mathrm{C}(31.2 \mathrm{wt} \%), \mathrm{S}(11.7 \mathrm{wt} \%), \mathrm{Ca}(11.2 \mathrm{wt} \%), \mathrm{Na}(1.3 \mathrm{wt} \%)$ and $\mathrm{K}(1.04 \mathrm{wt} \%)$. The powder later formulated into paste of various concentrations; $0.3 \%, 0.4 \%, 0.5 \%(\mathrm{w} / \mathrm{w})$. Extracted permanent premolar teeth were cleaned and stained with tea and coffee solutions. Formulations of S. persica fiber paste were then used to brush the teeth and being compared to commercial whitening toothpaste. The teeth shade changes were evaluated using VITAPAN® Classical Shade. After brushing under standardized condition using a brushing simulator machine, it was found that the staining of teeth buccal surface was reduced at least one tone of shade according to the VitaPan® shade.
\end{abstract}

\section{INTRODUCTION}

Personal appearance is very important in today's modern society where the aesthetic of teeth has become one of the main concerns. Strong desire for whiter teeth from both consumers and patient had caused the increasing use of tooth whitening products, thus leading manufacturers of oral care

* Corresponding Author

Nadia Halib, Faculty of Dentistry, Universiti Sains Islam Malaysia,

Level 15, Tower B, Persiaran MPAJ, Jalan Pandan Utama, Pandan Indah, 55100 Kuala Lumpur, Malaysia.

Email: nadia.halib@ usim.edu.my,Tel+603-42892400 products to constantly developing new formulations to meet this demand. (Pickles et al., 2005; White, 2001). Teeth discolouration can be divided into intrinsic, extrinsic or combination of both (Faiez et al., 1999; Joiner, 2004). Food containing tannins such as red wine, coffee and tea can give rise to extrinsic stain. With the increasing trends and popularity of branded coffee houses, multiple beverage choices are constantly available to individuals. Consumer however, are at the same time concerned about the effects of staining on their dentition. Coffee is very acidic, which allows penetration into the tooth surfaces and stain them. While tea contains tannins that again allow substances to adhere to the tooth and promote staining. As teeth become more porous, stain buildup and discoloration may increase. 
Depending on the amount and type of product, staining can be heavy and more difficult to remove. Besides, carotenes in oranges and carrots, tobacco use, whether it is smoking or chewing, also give rise to extrinsic stain (Watts and Addy, 2001; Joiner, 2006).

Tooth discolouration can be corrected by several means including whitening toothpastes, professional cleaning by scaling and polishing to remove stain and tartar, internal bleaching of nonvital teeth, external bleaching of vital teeth, microabrasion of enamel with abrasives and acid and placement of crowns and veneers (Sarrett, 2002; Joiner et al., 2002). Several professionally applied tooth bleaching products contain hydrogen peroxide and sometimes used together with a light or laser to accelerate or activate the whitening process (Goldstein, 1997). The mechanism involves free radicals breaking down pigments of discoloured teeth (Demarco et al., 2009; Claydon et al., 2004; Hilgenberg et al., 2011).

Some of carbamide and hydrogen peroxide containing bleaching products have been reported to have $\mathrm{pH}$ as low as 4.0 (Özcan et al. 2009). When the pH falls below 5.2, enamel demineralization (Claydon et al., 2004) and root resorption have been observed (Price et al., 2000). On the other hand, dentifrices are examples of over-the-counter whitening systems that contain abrasive agents such as hydrated silica, calcium carbonate, aluminium oxide, dehydrated calcium phosphate and perlite (Joiner, 2010). However, they have limited effectiveness by mechanically removing pigmentation off the teeth surface.

In some countries where brushing with toothbrushes are uncommon, brushing with chewing sticks have been practiced. Among the natural plant that has been utilised as chewing sticks for centuries is Salvadora persica. Many scientific studies have been carried out to evaluate the benefits of S. persica also known as miswak as an oral hygiene aid. It has antibacterial effects that disrupts plaque accumulation and promotes periodontal health (Allafi and Ababneh, 1995; Almas et al. 1997).

The cleansing efficacy of this plant have been offered by its mechanical effects of its fibers and the release of beneficial chemicals (Hardie and Ahmed, 1995) including chloride, fluoride, saponins, salvadorine, silica, sulfur, sterols, trimethylamine, and vitamin $\mathrm{C}$. The presence of silica is thought to acts as a natural abrasive material that give the mechanical effect of cleaning therefore removing stains and whitening the teeth (Fayez et al., 2016).

To the best of our knowledge, there is still no study that solely focus on $S$. persica whitening behavior. Therefore, this study was carried out to further investigate its potential as teeth whitening agents.

\section{MATERIALS AND METHODS}

\section{S. persica fiber preparation}

The bark of $S$. persica was peeled off. The pulp was oven dried and ground with mesh size 40 to produce powder.

\section{Scanning Electron Microscopy (SEM) and Energy dispersive X-ray spectroscopy (EDX)}

The $S$. persica pulp fiber and powder were mounted on an aluminium stub with double-sided carbon tape. The image and EDX analysis was carried out using Hitachi 1510 and Horiba Emax.

\section{Preparation of $S$. persica paste}

The powder was then formulated into paste with toothpaste base at three different concentration: $0.5 \%, 0.4 \%$ and $0.3 \%(\mathrm{w} / \mathrm{w})$.

\section{Teeth preparation}

The extracted permanent premolar human teeth were collected from out-patient dental clinic in Faculty of Dentistry, Universiti Sains Islam Malaysia (USIM). The reasons for tooth extraction and identifying characteristics (e.g. age, health, gender) of patients were not recorded therefore ethical approval was not required. Teeth were cleaned from blood and visible debris and heat-sterilized by autoclaving $\left(40 \mathrm{~min}, 120^{\circ} \mathrm{C}, 776 \mathrm{mmHg}\right)$. Teeth with restorations, carious lesions, obvious cracks or fractures were excluded from the study. Later, teeth were placed in $1 \mathrm{M}$ sodium hydroxide $(\mathrm{NaOH})$ for 48 hours to remove the pellicle. The cleaned teeth were kept in distilled water until used.

\section{Staining procedure}

A tea solution was prepared by boiling $36 \mathrm{~g}$ of tea in 800 $\mathrm{mL}$ of water for 10 minutes. A coffee solution was prepared using the same method. Teeth were individually incubated in each solution at $37^{\circ} \mathrm{C}$ for 24 hours. Following incubation, the teeth were immersed in $5 \mathrm{~mL}$ of distilled water for 10 minutes to remove any debris and allowed to dry on laboratory bench for 10 minutes.

\section{Simulated tooth brushing}

Simulated tooth brushing was done with a fabricated device with set parameters; brushing frequency of 2 strokes/second with a $10 \mathrm{~g}$ force applied. The $S$. persica paste was applied to the toothbrush with plane brush head and round bristles. The same method was applied for simulated tooth brushing using commercially available toothpaste as a positive control. The commercially available toothpaste claimed to be one shade whiter after one week.

Therefore, each tooth surface (buccal and occlusal) was brushed for 28 minutes respectively ( 2 minutes/each brushing X 2 times/day X 7 days). The whitening effects of the toothpastes were evaluated after this short period.

\section{Shade changes evaluation}

All teeth were evaluated using VITAPAN® Classical Shade according to the instrument direction. The shade of each tooth was recorded before staining, after staining with either coffee or tea, and after simulated brushing. The shade changes were observed over the buccal (B) and occlusal (O) surface of the teeth. 


\section{RESULTS AND DISCUSSION}

\section{S. persica fibre morphology and elemental analysis}

As shown in Figure 1, morphological analysis found that these fibres appeared to have blunt ends with a spongy structure. It was also observed that crystals of various shapes and sizes lodged within this spongy wood structure (Figure 2). These findings were in agreement with a study done by Sawidis (2013). The fibres were later ground to produce powder. It appeared that the grinding process did not cause the crystals to be lost or damaged (Figure 3). The preserved crystals in the powder helps retain the benefit of $S$. persica as tooth cleaning aid.

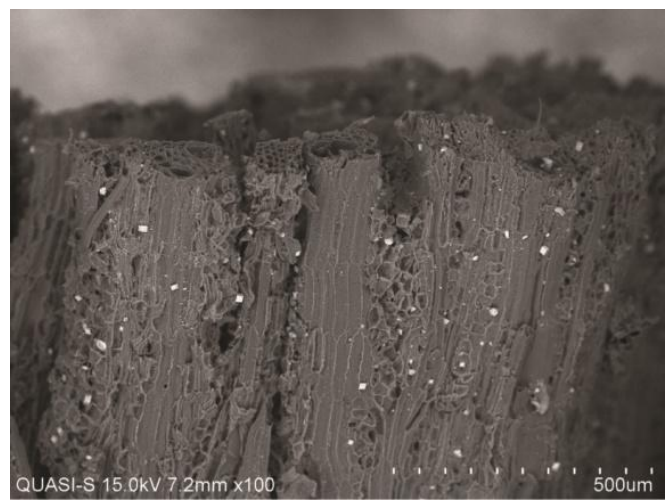

Fig. 1: $S$. persica fibre morphology.

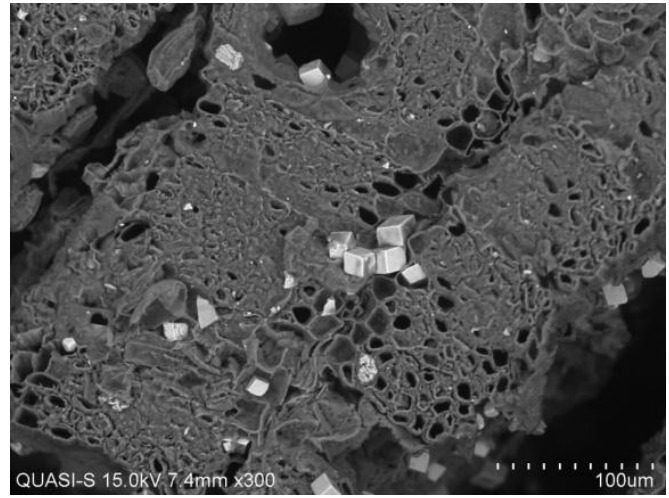

Fig. 2: Crystals lodge within $S$. persica fibre.

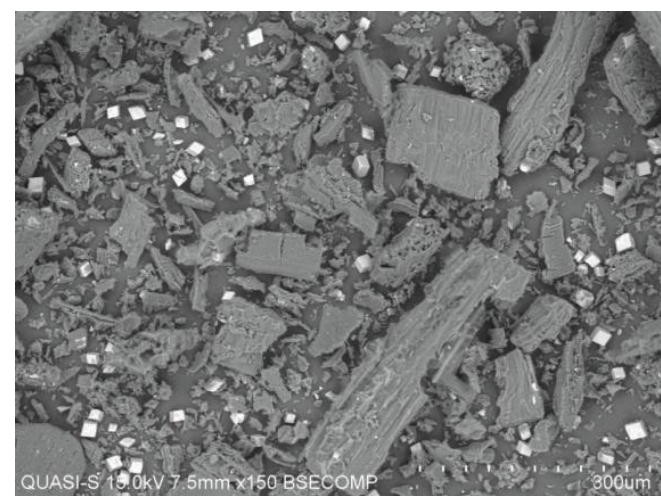

Fig. 3: $S$. persica fiber powder.

EDX was carried out to identify the mineral crystals and found that different crystal consists of different element. The rhomboidal crystals were constituted of O (43.44 wt\%), C (31.2 wt $\%), \mathrm{S}(11.7 \mathrm{wt} \%), \mathrm{Ca}(11.2 \mathrm{wt} \%), \mathrm{Na}(1.3 \mathrm{wt} \%)$ and $\mathrm{K}(1.04$ $\mathrm{wt} \%$ ) as shown in Figure 4.Whereas, as shown in Figure 5, the irregular crystals consisted of $\mathrm{C}(26.96 \mathrm{wt} \%), \mathrm{O}(45.37 \mathrm{wt} \%), \mathrm{Al}$ (0.54 wt $\%)$, Si (25.70 wt $\%), \mathrm{S}(0.38 \mathrm{wt} \%), \mathrm{K}(0.32 \mathrm{wt} \%), \mathrm{Ca}(0.34$ $\mathrm{wt} \%)$, and $\mathrm{Fe}(0.39 \mathrm{wt} \%)$.
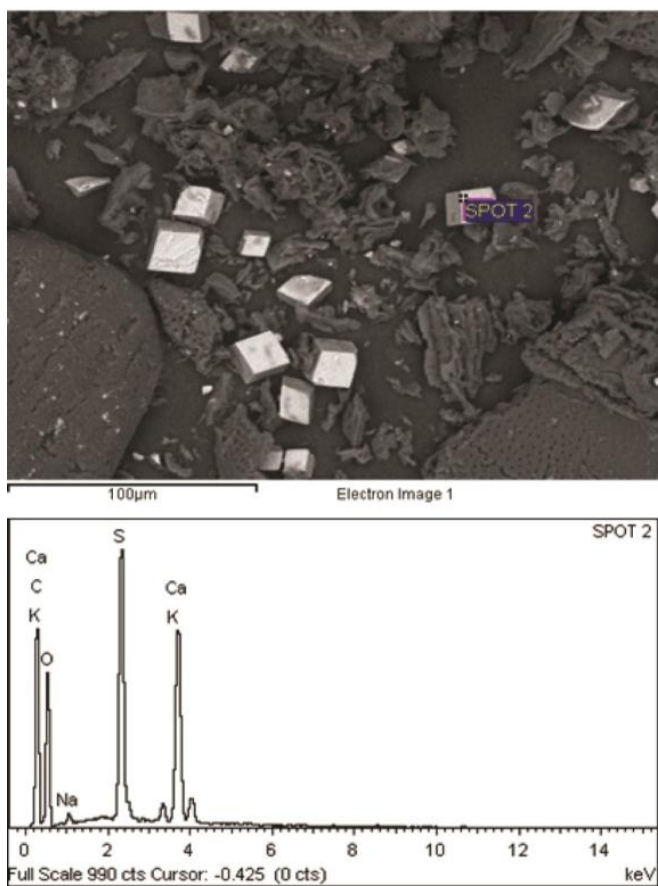

Fig. 4: EDX of rhomboidal crystals.
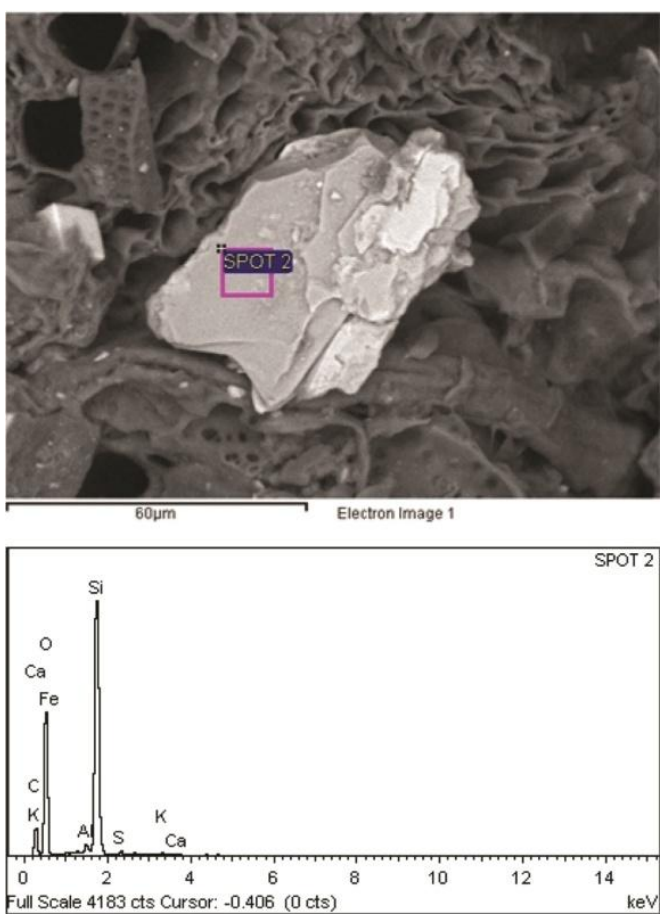

Fig. 5: EDX of irregular crystals.

All these elements were thought to have benefits for oral health. It has been speculated that $\mathrm{NaCl}, \mathrm{KCl}$ and sulphur- 
containing organic substances of $S$. persica could be responsible for its antibacterial effects against various oral aerobic and anaerobic bacteria (Al-lafi and Ababneh, 1995; Almas and AlBagieh, 1999). While according to another research, the presence of silica has been thought to contribute to miswak's mechanical action in plaque removal (Almas and Al-Lafi, 1995). In today's modern formulation, silica is added to toothpaste as an abrasive agent. Aside from silica, calcium carbonate is another compound that included in toothpaste formulation as polishing agents to remove plaque and other matter on teeth surface. Both are chosen because of their hardness is less than tooth enamel but hard enough to remove contaminating agent. This same mechanism may explain the whitening behavior of $S$. persica where these entire natural occurring crystals, act by removing pigment that attached to plaque and biofilm, which have caused discoloration.

\section{Tooth shades evaluation}

It this study, teeth stained with coffee or tea was brushed with different formulations of $S$. persica paste that were $0.5 \%$, $0.4 \%$ and $0.3 \%$ (w/w). Commercial whitening toothpaste was also used to brush one group of tooth as comparison. The shade changes on the buccal and occlusal surface of every premolar teeth were later evaluated by visual observation using VitaPan® shade. The VitaPan ${ }^{\circledR}$ shade visual assessment has previously been used successfully in many clinical studies (Kleberet al., 1998). Therefore, it was chosen to be used in this preliminary in-vitro study of $S$. persica whitening properties.

Table 1: Shade changes of teeth buccal surface stained with coffee and tea before and after brushing with $S$. persica paste compare to commercial tooth paste.

\begin{tabular}{|c|c|c|c|c|}
\hline \multirow[b]{2}{*}{$\begin{array}{l}\text { Type of } \\
\text { staining }\end{array}$} & \multirow[b]{2}{*}{ Treatment } & \multirow{2}{*}{$\begin{array}{c}\text { Tooth } \\
\text { sample } \\
\text { (Buccal } \\
\text { surface) }\end{array}$} & \multicolumn{2}{|c|}{ Tooth shade } \\
\hline & & & $\begin{array}{c}\text { Before } \\
\text { brushing }\end{array}$ & $\begin{array}{c}\text { After } \\
\text { brushing }\end{array}$ \\
\hline \multirow{4}{*}{ Coffee } & $0.5 \%$ S. persica & $\mathrm{A}$ & A4 & A2 \\
\hline & $0.4 \%$ S. persica & B & D4 & D1 \\
\hline & $0.3 \%$ S. persica & $\mathrm{C}$ & $\mathrm{C} 4$ & $\mathrm{C} 2$ \\
\hline & Commercial toothpaste & $\mathrm{D}$ & $\mathrm{C} 2$ & $\mathrm{C} 1$ \\
\hline \multirow{4}{*}{ Tea } & $0.5 \%$ S. persica & $E$ & C3 & $\mathrm{C} 1$ \\
\hline & $0.4 \%$ S. persica & $\mathrm{F}$ & C3 & $\mathrm{C} 1$ \\
\hline & $0.3 \%$ S. persica & G & $\mathrm{C} 1$ & $\mathrm{C} 1$ \\
\hline & Commercial toothpaste & $\mathrm{H}$ & $\mathrm{C} 4$ & $\mathrm{C} 2$ \\
\hline
\end{tabular}

Table 2: Shade changes of teeth occlusal surface stained with coffee and tea before and after brushing with $S$. persica paste compare to commercial toothpaste.

\begin{tabular}{|c|c|c|c|c|}
\hline \multirow[b]{2}{*}{$\begin{array}{l}\text { Type of } \\
\text { staining }\end{array}$} & \multirow[b]{2}{*}{ Treatment } & \multirow{2}{*}{$\begin{array}{c}\text { Tooth } \\
\text { sample } \\
\text { (Occlusal } \\
\text { surface) }\end{array}$} & \multicolumn{2}{|c|}{ Tooth shade } \\
\hline & & & $\begin{array}{c}\text { Before } \\
\text { brushing }\end{array}$ & $\begin{array}{c}\text { After } \\
\text { brushing }\end{array}$ \\
\hline \multirow{4}{*}{ Coffee } & $0.5 \%$ S. persica & $\mathrm{A}$ & $\mathrm{C} 4$ & $\mathrm{C} 2$ \\
\hline & $0.4 \%$ S. persica & B & A4 & A1 \\
\hline & $0.3 \%$ S. persica & $\mathrm{C}$ & A4 & $\mathrm{A} 2$ \\
\hline & Commercial toothpaste & $\mathrm{D}$ & $\mathrm{C} 2$ & $\mathrm{C} 1$ \\
\hline \multirow{4}{*}{ Tea } & $0.5 \%$ S. persica & $\mathrm{E}$ & $\mathrm{C} 3$ & $\mathrm{C} 1$ \\
\hline & $0.4 \%$ S. persica & $\mathrm{F}$ & $\mathrm{C} 4$ & $\mathrm{C} 1$ \\
\hline & $0.3 \%$ S. persica & $\mathrm{G}$ & $\mathrm{C} 3$ & $\mathrm{C} 1$ \\
\hline & Commercial toothpaste & $\mathrm{H}$ & $\mathrm{C} 3$ & $\mathrm{C} 2$ \\
\hline
\end{tabular}

The tooth shades were evaluated under direct two fluorescent lights and whitening was defined as a change of at least one-tone of shade in the VitaPan ${ }^{\circledR}$. Shows in Table 1 and Table 2 were shade changes according to VitaPan ${ }^{\circledR}$ (Figure 6) on the buccal and occlusal surface respectively. While Figure 7 and Figure 8 shows visual shade changes of teeth stained with coffee and tea brushed with $0.5 \%$ (w/w) $S$. persica paste. Whereas Figure 9 shows visual shade changes of teeth stained with coffee and brushed with commercial whitening toothpaste. It was discovered that formulations of $0.5 \%$ and $0.4 \% \mathrm{~S}$. persica paste whitening the teeth buccal surface better than $0.3 \% \mathrm{~S}$. persica paste. The shade changed at average of two tones and these findings were comparable to the effect of commercial whitening toothpaste.

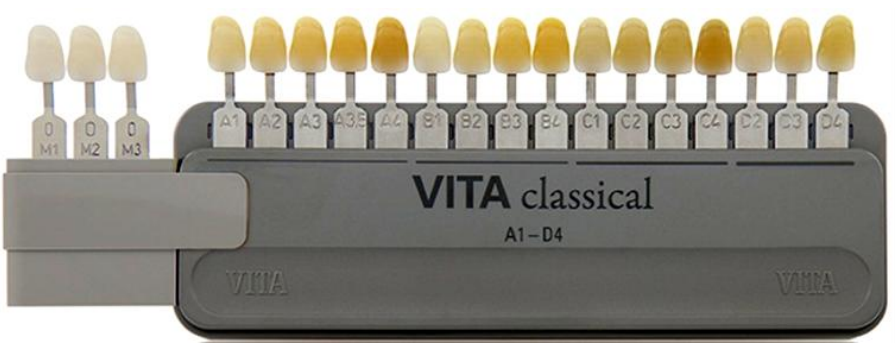

Fig. 6: VitaPan® shade

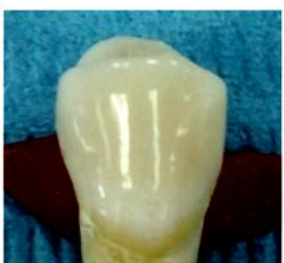

(a)

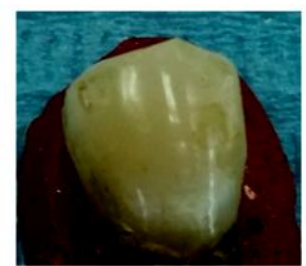

(b)

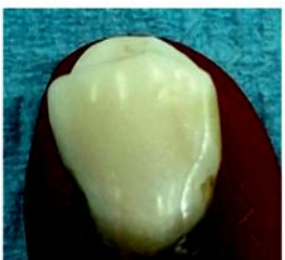

(c)
Fig. 7: Shade changes of tooth buccal surface stained with coffee and brushed with $0.5 \%(\mathrm{w} / \mathrm{w}) \mathrm{S}$. persica paste. (a)Tooth before stained. (b)Stained tooth before brushing. (c)Stained tooth after brushing.

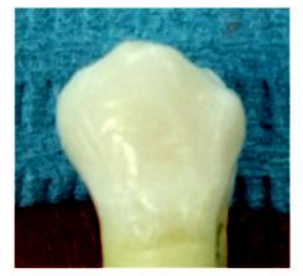

(a)

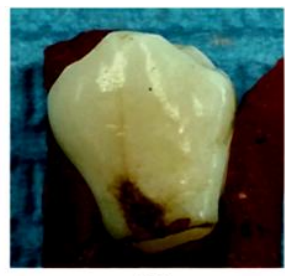

(b)

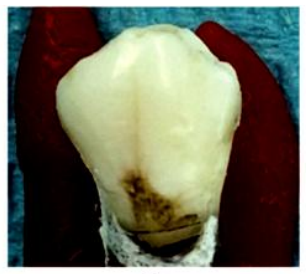

(c)
Fig. 8: Shade changes of tooth buccal surface stained with tea brushed with $0.5 \%$ (w/w) S. persica paste. (a)Tooth before stained. (b)Stained tooth before brushing. (c)Stained tooth after brushing.

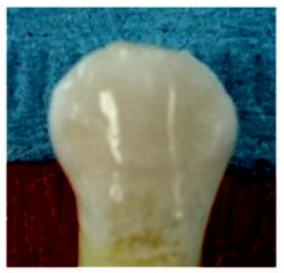

(a)

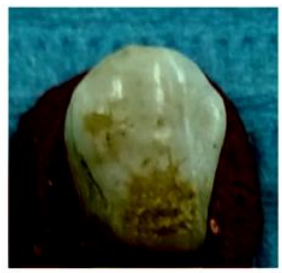

(b)

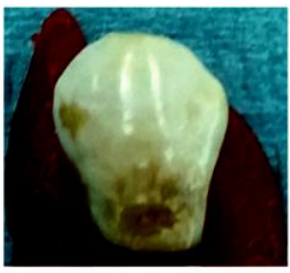

(c)
Fig. 9: Shade changes of tooth buccal surface stained with coffee and brushed with commercial toothpaste. (a)Tooth before stained. (b)Stained tooth before brushing. (c)Stained tooth after brushing. 
Joiner (2007) has outlined that abrasive cleaning process is affected by several factors including particle hardness, shape, size distribution, concentration and applied load. It has also been shown that as the abrasive particle concentration increases the abrasion will increase until the chances of particles being captured by the brush approaches unity. Any further addition of particles will be ineffective at increasing the rate of abrasion, leading to a plateau level of stain removal efficacy (Dawson et al., 1998). These explained why $0.4 \%$ S. persica concentration gave better effect as compared to $0.3 \%$ concentration. In addition, the increase of $S$. percisa concentration from $0.4 \%$ to $0.5 \%$ did not give any increase in whitening efficacy since it has reached a plateau level. Another interesting aspect to be discussed is the combinations of abrasives that were shown to be efficacious. As demonstrated in a study, the incorporation of perlite (an amorphous glassy silicate) into a silica based toothpaste gave a significant improvement in stain removal properties when compared to a control silica toothpaste in both in vitro and clinical studies (Joiner et al., 2002). While the incorporation of perlite into a calcium carbonate based whitening toothpaste has been shown in clinical studies to significantly remove existing natural extrinsic stains after 2 weeks (Collins et al., 2005). Naturally, S. persica contained a lot of crystals of different shapes and sizes. This creates the environment of mix abrasive systems, which help increase its effectiveness. Furthermore, the crystals were originated from different minerals that exhibited and possess different hardness and properties. The irregularity of some crystal might add uniqueness where it can reach various angulations of teeth surface morphologies. In addition, $S$. persica fibre itself contributed in the mechanical cleaning effects that enhance its whitening ability.

\section{CONCLUSION}

In conclusion, $S$. persica paste has the potential of being an effective, alternative teeth-whitening product especially for removing extrinsic staining. This might be due to the presence of crystals that act as natural occurring abrasive agent. The preliminary assessment was done by visual evaluation. A detail and more technical evaluation of its whitening effect can be further studied using lab instrument for accuracy. It is our interest to continue evaluating its whitening mechanism in the near future.

\section{ACKNOWLEDGEMENT}

Financial support and sponsorship: The author would like to acknowledge the Ministry of Higher Education (MOHE), Malaysia for the Fundamental Research Grant Scheme (FRGS/1/2014/SG06/USIM/02/1) that has funded this study.

Conflict of Interests: There are no conflicts of interest.

\section{REFERENCES}

Al-lafi $\mathrm{T}$ and Ababneh $\mathrm{H}$. The effect of the extract of the miswak (chewing sticks) used in Jordan and the Middle East on oral bacteria. Int Dent J, 1995; 45: 218-22.

Almas K and Al-Bagieh NH. The antimicrobial effects of bark and pulp extracts of miswak, Salvadorapersica. Biomed Lett, 1999; 60: 71-75.
Almas $\mathrm{K}$ and Al-Lafi TR. The natural toothbrush. World Health Forum, 1995; 16: 206-210.

Almas K, Al-Bagieh N, Akpata ES. In vitro antibacterial effect of freshly cut and 1-month-old miswak extracts. Biomed Lett, 1997; 56: 145-149.

ClaydonNCA, Moran J, Bosma ML, Shirodaria S, Addy M, Newcombe R. Clinical study to compare the effectiveness of a test whitening toothpaste with a commercial whitening toothpaste at inhibiting dental stain. J ClinPeriodontol, 2004; 31: 1088-1091.

Collins LZ, Naeeni M, Schafer F, Brignoli C, Schiavi A, Roberts J, Colgan P. The effect of a calcium carbonate/perlite toothpaste on the removal of extrinsic tooth stain in two weeks. Int Dent J, 2005; 55: 179-82.

Dawson PL, Walsh JE, Morrison T, Grigor J. Dental stain prevention by abrasive toothpastes: a new in vitro test and its correlation with clinical observations. J Cosmet Sci, 1998; 49: 275-83.

Demarco FF, Meireles SS, Masotti AS. Over-the-counter whitening agents: a concise review. Braz Oral Res, 2009; 23(Suppl 1): 64-70.

Faiez N, Muawia A, Qudeimat AS, Al-Rimawi. Dental Discolouration: An Overview. J Esthet Restor Dent, 1999; 11(6): 291-310.

Fayez N, Mustafa N, Zohaib K Muhammad SZ and Khalid. Role of Salvadorapersica chewing stick (miswak): A natural toothbrush for holistic oral health. Eur J Dent, 2016; 10(2): 301-308.

Goldstein RE. In-office bleaching: Where we came from, where we are today. J Am Dent Assoc, 1997; 128(suppl): 11S-15S.

Hardie $\mathbf{J}$ and Ahmed $\mathrm{K}$. The miswak as an aid in oral hygiene. $\mathrm{J}$ Phillip Dent Assoc, 1995;47: 33-38.

Hilgenberg SP, Pinto SC, Farago PV, Santos FA, Wambier DS. Physical- chemical characteristics of whitening toothpaste and evaluation of its effects on enamel roughness. Braz Oral Res, 2011; 25: 288-294.

Joiner A, Pickles MJ, Matheson JR, Weader E, Noblet L, Huntingdon E. Whitening toothpastes: effects on tooth stain and enamel. International Journal of Dentistry, 2002; 52: 424-30.

Joiner A, The cleaning of teeth. Johansson I, Somasundaran P, editors. Handbook for cleaning/decontamination of surfaces, 2007; vol. 1: 371405.

Joiner A. The bleaching of teeth: a review of the literature. Journal of Dentistry, 2006; 34:412-9.

Joiner A. Tooth color: a review of the literature. Journal of Dentistry, 2004; 32(Suppl. 1):3-12.

Joiner A. Whitening toothpastes: A review of the literature. Journal of Dentistry, 2010; 38(Suppl): e17 - e24.

Kleber CJ, Moore MH, Nelson BJ. Laboratory assessment of tooth whitening by sodium bicarbonate dentifrices. Journal of Clinical Dentistry, 1998; 9: 72-5.

ÖzcanCakmakçioglu, Pinar Yilmaz, BülentFaikTopbaoi. Clinical evaluation of whitening effect of whitening toothpastes: A pilot study. OHDMBSC, 2009; VIII(No. 4): 6-13.

Pickles MJ, Evans M, Philpotts CJ, Joiner A, Lynch RJM, Noel N, Laucello $\mathrm{M}$. In vitro efficacy of a whitening toothpaste containing calcium carbonate and perlite. Int Dent J, 2005; 55: 197-202.

Price RBT, Sedarous M, Hiltz GS. pH of tooth-whitening products. J Can Dent Assoc, 2000; 66: 42-6.

$1535-8$.

Sarrett DC. Tooth whitening today. J Am Dent Assoc, 2002; 133:

Sawidis T. Anatomy and Ultrastructure of Salvadora persica Stem: Adaptive To Arid Conditions And Beneficial For Practical Use. Acta BiolCracov Ser Bot, 2013; 55/2: 7-17.

Watts A and Addy M. Tooth Discolouration and Staining: A Review Of The Literature. Br. Dent. J., 2001; 190(6): 309-16.

White DJ. Development of an improved whitening dentifrice based upon "stain-specific soft silica" technology. Journal of Clinical Dentistry, 2001; 12: 25-9. Spec. Iss. 2.

How to cite this article:

Halib N, Nuairy NB, Ramli H, Ahmad I, Othman NK, Salleh SM, Bakarudin SB. Preliminary Assessment of Salvadora persica Whitening Effects on Extracted Stained Teeth. . J App Pharm Sci, 2017; 7 (12): 121-125. 